\title{
Die noodsaaklike onderskeiding tussen pastoraat en evangelisasie ten opsigte van die probleem van kerklosheid en kerkloosheid
}

\author{
TFJ DREYER
}

\section{INLEIDING}

Toenemende kerklosheid en kerkloosheid dwarsoor die Christelike wêreld, het die kerk geprikkel om opnuut weer te besin oor die evangelisasiewerk van die kerk, as antwoord op die probleem. Dit het daartoe gelei dat in die laaste aantal jare, daar vanuit alle kerklike oorde, 'n steeds toenemende stroom publikasies die lig gesien het, om hierdie probleem te ondersoek, en as antwoord daarop evangelisasiemetodes en -praktyke daar te stel. 'n Mens kan maar net na enkele van die publikasies kyk om te besef dat daar op die terrein van die evangelisasie groot verwarring heers. 'n Verskeidenheid definisies van evangelisasie word aangebied en elke definisie gee weer aanleiding tot ' $n$ ander benaderingswyse en metode.

Beukes (1983: 45) merk tereg op dat daar geen eenstemmigheid bestaan oor wat met evangelisasie bedoel word nie, veral nie oor die doel en objek van evangelisasie nie. De Klerk (1979: 7) stel dat sommige groepe onder evangelisasie, die sogenaamde "inwendige sending" verstaan, teenoor die uitwendige sending na buite. Hiermee word bedoel dat in die breë volkskerk met sy grootskaalse vervreemding, moet die verkondiging van die Woord hand aan hand loop met filantropiese arbeid aan behoeftiges: "Groot klem val op die Christelike strewe tot die sosiale verbetering ... Wat Wichern hier so sterk beklemtoon, word in die Gereformeerde kerke hoofsaaklik onder die diens van barmhartigheid tuisgebring" (De Klerk 1979: 7; vgl. ook Walker 1965: 504).

Margulle (1959: 294) sê dat evangelisasie die arbeid aan die heiden in die Weste is, terwyl sending die werk in ander kontinente is. "Die Angelsaksiese teologie neem ten opsigte van evangelisasie oorwe- 
gend en hoofsaaklik die standpunt in dat dit 'n omnibusbegrip is, waarin beide die sending na die heiden as die konfrontrasie van die kerklidmaat met die evangelie opgeneem word" (De Klerk 1979: 8). Die sogenoemde "evangeliese groep" het tydens die konferensies van Berlyn en Lausanne hulle beleid, wat daarop neerkom dat onder evangelisasie alle arbeid binne die gemeente verstaan word en ook alle arbeid onder vervreemdes en heidene, met die aksent op toegespitse evangelieverkondiging (kyk Beukes 1983: 51). Evangelisasie kom ook na vore in die kringe van die politieke teologie met sy maatskappy-kritiek. Vir hulle impliseer evangelisasie die roeping van die kerk om in al sy dienswerk sosiaal betrokke te raak in die gemeenskap, sodat die kerk alle vorme van ongeregtigheid uitskakel (kyk De Klerk 1979: 10). Met reg kan gesê word dat by die meeste evangelisasie-aksies, evangelisasie die towerwoord geword het, wat alles omvat.

Hierdie verwarrende situasie veroorsaak dat die verskillende gestaltes van die kerklike verkondiging en arbeid so vervloeid raak dat evangelisasie enersyds self nêrens spesifiek tot sy reg kom nie, of andersyds, dat die ander gestaltes van die verkondiging hulle eiesoortige karakter verloor.

As die kerk werklik ernstig aandag wil gee aan die probleem van kerklosheid en kerkloosheid, is dit dringend noodsaaklik dat die verskillende gestaltes van die kerklike verkondiging, met die oog op teologiese besinning en beplanning, van mekaar onderskei moet word. Hierdie onderskeiding mag aanvanklik baie tegnies en formeel voorkom, maar sistematiese teologiese besinning is noodsaaklik vir'n doelmatige verkondigingspraktyk.

\section{ONDERSKEIDING}

Die verkondiging van die kerk val uiteen in verskillende gestaltes. Hierdie onderskeiding word hoofsaaklik deur twee faktore beïvloed, naamlik die objek en doel van die verkondigingsgestaltes. Die eerste is die voorgemeentelike gestalte, naamlik die sending. Die objek van die sendingverkondiging is hulle wat nog-nie-glo-nie, met ander woorde die heidenwêreld. As doel van die sending kan ons stel die stigting van die geloof. Binnegemeentelik funksioneer verskeie verkondigingsgestaltes, met as gemeenskaplike objek hulle wat doop-of-belydende lidmate van die kerk is, asook 'n oorkoepelende doel, naamlik die opbou van die geloof. Hierdie gestaltes word 
verder gedifferensieer ten opsigte van vorm en metode en val dan uiteen in prediking (sakramente), pastoraat en kategese. Die volgende kategorie is die postgemeentelike gestalte, naamlik die evangelisasie. As objek van die evangelisasie geld dan diegene wat niemeer-glo-nie, met die doel om hulle weer tot geloof te bring en terug te lei na die kerk. Die toegangspoort tussen voorgemeentelik en binnegemeentelik is die doop en/of belydenis, terwyl die grens tussen binnegemeentelik en postgemeentelik weer die kerklike tug en eventueel die ban is. In 'n sekere sin is hierdie postgemeentelike gestalte van die verkondiging tegelyk ook weer voorgemeentelik van aard (vgl. De Wet s a).

Hierdie sistematisering en onderskeiding is nodig vir 'n sinvolle gestaltegewing van die kerklike verkondiging in elke situasie. Hieruit is dit duidelik dat die vorm, en in gekwalifiseerde sin ook die metode, bepaal sal word deur die objek en die doel van die bepaalde verkondigingsgestalte.

As die kerk dus wil besin oor die evangelisasie, sal hy eers duidelik die vraag moet beantwoord: wie wil hy evangeliseer en wat wil hy daarmee bereik? Wanneer hierdie onderskeiding losgelaat word, word evangelisasie 'n verwarrende omnibusbegrip wat kan beteken dat alle mense binne die kerk objek van evangelisasie is, met die doel om hulle tot dieper "geestelike belewing" te bring, of mense binne en buite die kerk word vir die doel van evangelisasie gelykgeskakel as objek, sonder 'n spesifieke vorm, metode of evangelisasiedoel.

\section{VERVLOEIING VAN GRENSE}

In die huidige praktyk van die kerklike lewe is dit nie so maklik om die genoemde onderskeiding en sistematisering te handhaaf nie. Hierdie onderskeiding vervloei in die praktyk. Die onderskeie gestaltes van die verkondiging dien die een oorkoepelende verkondigingsdoel. Daarom sal die prediking byvoorbeeld kategetiese elemente bevat en sal die pastoraat op sy beurt weer kategetiese en evangeliserende elemente insluit. Die grense van die verkondigingsgestaltes vervaag ook as gevolg van die realiteit dat die grense van die kerk vervaag het. Tereg stel De Klerk (1979: 20) dat die sirkels van binnegemeentelik, voorgemeentelik en postgemeentelik mekaar sny en dikwels oorvleuel: "Ons verwys hier na die altyd groter wordende randkerklikheid wat dikwels reeds totale buitekerklikheid 
beteken, terwyl die randkerklikes nog steeds veronderstel is om in die gemeente-terrein met sy ampsbediening te ressorteer." So kan ook die sirkels van sending en evangelisasie mekaar sny, byvoorbeeld waar kulturele invloede van die Christelike beskawing mense beïnvloed het tot 'n sosiaal-Christelike lewenspatroon, terwyl die geloof in Jesus Christus afwesig is.

Ons wil ons egter slegs bepaal by die vervloeiing van grense tussen binne- en postgemeentelike verkondiging. Hierdie vervaging in grense is hoofsaaklik te wyte aan die verwatering van die kerklike opsig en tug. Die vadere het reeds gesê dat die tug saam met die suiwere evangelieverkondiging en bediening van die sakramente die kenmerke van die ware kerk is (Nederlandse Geloofsbelydenis, artikel 29). Die tug is in gekwalifiseerde sin, die grens van die kerk. Waar die opsig en tug verwaarloos word, begin die grense van die kerk vervaag. Daarom is die realiteit waarmee die kerk gekonfronteer word so problematies omdat daar formeel lidmate aan die kerk behoort, wat streng gesproke eintlik reeds buite die kerk is. Om hierdie probleem die hoof te bied moet die kerke evangeliseer. Die vraag is egter: wie moet die kerk evangeliseer? Is dit diegene wat formeel aan geen kerk behoort nie, maar tog deel van die eie volk is? Is dit diegene wat formeel nog wel aan die kerk behoort, maar nie meer aktief meeleef nie? Indien dit wel laasgenoemde kategorie is, waar lê die grens tussen aktiewe en onaktiewe lidmate? Die praktiese situasie van die evangelisasiestandplaas van die Hervormde Kerk in Pretoria het aan die lig gebring dat die meeste persone wat onder die evangelisasie bearbei word, diegene is wat wel nog formeel aan die kerk behoort, maar onaktief geraak het (vgl. Malan 1983).

Hierdie vervloeiing van grense gee daartoe aanleiding dat vanweë die verleentheid om die objek van evangelisasie te identifiseer, evangelisasieaksies geloods word met as objek die hele kerk. Dan word evangelisasie ' $n$ omnibusbegrip en beteken dit in praktyk dat die hele kerk tot "herlewing" moet kom. Aan die ander kant kan dit tot gevolg hê dat evangelisasie nie in die kerk tot sy reg kom nie, omdat die kerk vanweë sy onvermoë van die objek te identifiseer, nie die omvang en erns van die probleem besef nie?

Wanneer evangelisasie so vervloei en vervaag, beskou sommige ampsdraers dit as oorbodig omdat dit bloot ' $n$ duplisering van ander verkondigingsgestaltes soos byvoorbeeld die pastoraat is. Omdat evangelisasie in 'n lugleegte moet funksioneer gaan dit ook mank 
aan 'n eie vorm en metode. Wat maak die evangelisasiegesprek dan anders as 'n gewone pastorale gesprek.

\section{NOODSAAKLIKE IDENTIFISERING VAN OBJEK}

Om in hierdie verwarrende gegewenheid 'n doelmatige evangelisasiemetode daar te stel, is dit dwingend noodsaaklik dat voor alles die objek van pastoraat en evangelisasie geïdentifiseer en onderskei word. Die enigste wyse waarop die kerk dit effektief kan doen is om die kerklike opsig en tug weer konsekwent te laat funksioneer. Dit kan alleenlik plaasvind indien 'n doeltreffende kontrolesisteem in werking gestel word, wat die uitoefening van die opsigtaak van die ouderling en predikant sinvol kan koördineer. By wyse van die ouderlingsverslag kan lidmate wat kerklik onaktief geraak het maklik geïdentifiseer word. Hierdie lidmate wat as kerklos geïdentifiseer is, word die objek van die besondere pastoraat. Dit beteken dat predikant en ouderling op 'n meer intensiewe wyse as die gewone huisbesoek, by die lidmate betrokke sal raak. Wanneer daar intensief en met geduld en liefde, onder die pastoraat met hulle gehandel is en daar geen verandering intree nie, sal die kerkraad ook bereid moet wees om met hulle die pad van die kerklike tug te bewandel, wat eventueel mag uitloop op die beëindiging van lidmaatskap. Hierdie persoon is dan kerkloos en is dan formeel die objek van evangelisasie, saam met ander wat deur hulle doop of opvoeding, of kulturele agtergrond, binding met die kerk gehad het.

Die identifisering van die objek lei dus tot twee kategorieë: diegene wat kerklos is, is die objek van die besondere pastoraat en diegene wat kerkloos geraak het, is die objek van die evangelisasie.

\section{VOORDELE VAN HIERDIE ONDERSKEIDING}

Op blote gesigswaarde geoordeel, mag hierdie onderskeiding tegnies en kunsmatig lyk en dit mag ook in sekere opsigte waar wees, byvoorbeeld: so 'n gesprek onder die besondere pastoraat sal reeds in wese evangelisasiemomente bevat. Alhoewel dit waar is, hou hierdie onderskeiding tussen pastoraat en evangelisasie tog voordele in vir 'n doelmatige aanpak van die probleem van kerklosheid en kerkloosheid. 


\subsection{Intensiewe pastorale bearbeiding van die kerklosse}

In die praktyk van die kerklike lewe gebeur dit dat lidmate vir 6 maande of 'n jaar of selfs langer kerklik onaktief raak, of reeds is vir 'n baie langer periode. Met kerklik-onaktief bedoel ons dié lidmate wat nie meer gereeld eredienste bywoon en nie meer deel het aan gemeentelike aktiwiteite nie. Praktiese ervaring het aan die lig gebring dat lidmate in die meeste gevalle, alhoewel hulle kerklik onaktief geraak het, nogtans bereid is om aan die diaken ' $n$ offergawe vir die kerk te gee. Hierdie "skynbare" kerklike betrokkenheid deur middel van die gee van offergawes, is dikwels vir beide die lidmaat en die ampsdraers, ' $n$ mate van gerusstelling dat dié lidmaat nog kerklik betrokke is. Dit gee in baie gevalle daartoe aanleiding dat sulke lidmate gewoonweg besoek en bearbei word tydens huisbesoek met die verswygde gerusstelling dat die lidmaat darem nog lidmaat van die kerk is. Tydens 'n huisbesoekgesprek van die ouderling of predikant sal so'n lidmaat na alle waarskynlikheid gemaan word tot beter erediensbywoning, maar dit word daarby gelaat tot by 'n volgende huisbesoekgesprek. Hierdie situasie kan vir maande en jare voortduur, sonder enige noemenswaardige reaksie van die lidmaat en tot frustrasie van ampsdraers. So ontstaan daar geleidelik die situasie dat in gemeentes talle lidmate is wat wel nog formeel lidmate van die kerk is, op die lidmaatregister van gemeentes staan, deur ampsdraers gereeld besoek word, maar nogtans in wese sterwende lidmate geword het.

Deur sy "normale" optrede en besoeke deur predikant, ouderling en diaken, is die kerk dikwels onbewustelik besig om die status quo van die lidmaat te sanksioneer en daarom medeverantwoordelik vir die kerklosheid van lidmate te word. Die feit dat die ampsdraers hom "normaalweg" bearbei, gee aan die kerkloslidmaat die gemoedsrus dat die kerk hom nie verwerp of vermy nie en dat hy daarom nog aanvaarbaar is. Hy beleef dit naderhand ook maar as die "normale" plig van die ouderling of predikant om tydens huisbesoek hom te konfronteer oor sy swak kerkbesoek. Na so 'n konfrontasiegeleentheid sal hy miskien sporadies die erediens bywoon, as illustrasie van die feit dat hy darem ag gee op hulle vermaning. Met hierdie enkele sporadiese bywoning het hy dan ook sy gewete gesus. Die feit dat hy offergawes gee, is dikwels vir so 'n kerklosse die salf vir sy gewete omdat hy daarmee sigbaar illustreer dat hy hom nie van die kerk losgemaak het nie, en dat die kerk dit so aanvaar. 
As die kerk daadwerklike aandag aan die probleem van kerklosheid wil gee, sal hy in die eerste instansie hierdie bedieningspatroon waarin die feit van kerklosheid stilswyend gesanksioneer en genormaliseer word, moet deurbreek. Indien ouderlinge gereeld, skriftelik verslag doen van hulle wyk en sulke verslae tydens 'n ouderlingvergadering behandel word, kan sulke lidmate betyds geidentifiseer word as kerklosses. Hierdie identifikasie van lidmate wat kerklos is, moet dan daartoe lei dat per besluit van die vergadering hulle die objek word van geïntensiveerde pastorale bearbeiding, deur beide die predikant en wyksouderling. Vir dié doel kan selfs 'n ouderling wat in die besonder daarvoor geskik is, afgesonder word. Tydens hierdie besondere besoek sal die lidmaat duidelik moet verstaan dat sy kerklosheid onder die aandag van die kerkraad gekom het, dat hulle in opregte bewoënheid daaroor besorgd is en daarom in die besonder aandag aan hom wil wy. Dit sal dadelik by die lidmaat die besef bring dat sy kerklosheid nie deur die kerk as "normaal" beskou of aanvaar word nie. Omdat hierdie persoon die objek van die pastoraat, as binnegemeentelike gestalte van die verkondiging is, kan in sulke gesprekke 'n appèl gemaak word op die lidmaat se doop en belydenis van geloof. Van daaruit kan die konsekwensie getrek word, dat geloof ook 'n noue verbondenheid met die erediens, sakramente en gemeenskap van gelowiges impliseer en veronderstel. Onder die pastoraat aan die kerklosse is daar dus alreeds ' $n$ vertrekpunt en klankbodem, naamlik sy formele verbintenis aan die kerk deur doop en belydenis.

'n Volgende eventuele stap in hierdie besondere pastorale bearbeiding kan byvoorbeeld ook wees dat onder die lidmaat se aandag gebring word dat die kerk nie meer langer sy offergawe sal aanvaar nie, omdat offergawes sonder 'n gepaardgaande geloofslewe skyn is. Die praktyk het bewys dat die lidmaat dan in baie gevalle besef dat hy besig is om sy formele binding met die kerk te verbreek en dan dikwels eers die werklike openheid tot gesprek openbaar.

Indien selfs dit geen reaksie tot gevolg het nie, sal die ampsdraers uiteindelik daartoe moet oorgaan om met die lidmaat te handel volgens die kerklike tug. Hierdie geïntensiviseerde bearbeiding sal natuurlik voortdurend gedra en gekenmerk moet word deur die gesindheid van liefde en geduld. Kerkrade het al in baie gevalle die effektiwiteit van die tug in sulke gevalle bevraagteken en as gevolg daarvan die tug verwaarloos. Praktiese ervaring het egter bewys dat die effektiwiteit van die kerklike tug, wat in die regte gesindheid 
hanteer word, nie geringgeskat moet word nie 1 . Op hierdie stadium kom die lidmaat gewoonlik tot die besef dat die kerk sy handelswyse nie aanvaar nie en dat hy gevaar loop om sy lidmaatskap te verbeur. Dit bring hom gewoonlik tot die besef van die erns van sy eie posisie en bring rypheid vir 'n sinvolle gesprek. Die tughandeling het dikwels die newe-effek, dat deur die afkondiging daarvan in die gemeente, ander kerklosses onder die besef kom van die werklikheid dat die kerk so 'n leefwyse nie sanksioneer of aanvaar nie.

Die laaste stap wanneer geen verandering ingetree het nie, sal uiteindelik die beëindiging van formele lidmaatskap beteken ${ }^{2}$. Die voordele van die bearbeiding van die kerklosse onder die pastoraat is dus voor die handliggend:

5.1.1 Die lidmaat kan aangespreek word op grond van sy doop en belydenis as basis van gesprek.

5.1.2 Die besondere pastorale bearbeiding bevry die lidmaat van sy illusie van normaliteit.

5.1.3 Die opsig en die tug bring die lidmaat onder die besef van die konsekwensies van sy kerklosheid en dra by tot gesprekrypheid.

5.1.4 Die tug het ook die newe-effek dat dit ander lidmate tot die besef bring van die onversoenbaarheid van "geloof" en kerklosheid.

\subsection{Evangelisasie van die kerklose}

As hierdie identifisering en onderskeiding tussen kerklosse en kerklose as objek van die pastoraat en evangelisasie onderskeidelik, losgelaat word, verval die voordele van sodanige bearbeiding soos genoem in 5.1-5.4. Omdat geen spesifieke persoon as objek van evangelisasie geïdentifiseer is nie, lei dit daartoe dat in die praktyk geen aandag aan evangelisasie gegee word nie, of die hele gemeente word geëvangeliseer tot herlewing, met net sulke verwarrende gevolge.

Die onderskeiding tussen pastoraat en evangelisasie bied egter die moontlikheid dat daar sinvol en sistematies aan beide die kerklosse en kerklose aandag gegee word. Die persone genoem in 5.1 van wie die formele lidmaatskap van die kerk beëeindig is, word dus saam met ander volksgenote wat slegs doop- of kulturele verbintenis met die Christelike kerk het, die objek van evangelisasie. Vanweë die objek vereis die evangelisasiegesprek 'n ander invalshoek, ge- 
spreksbasis en vorm. Basiese geloofswaarhede sal uitgespel moet word; filosofiese of ideologiese voorveronderstellings as obstruksie vir 'n sinvolle gesprek, sal opgeklaar moet word; in die geval van dooplidmate sal die doop en onverbreekbare trou van God as vertrekpunt kan geld; kategese sal hier 'n prominente rol moet vervul; agressie, afweermeganismes en oordragverskynsels vanuit vorige ervarings met die kerk en/of sy ampsdraers sal erken en hanteer moet word.

Uit bogenoemde is dit reeds duidelik dat wanneer die objek van die evangelisasie duidelik geïdentifiseer word, dit 'n eie inhoud, benaderingswyse en metode bied, as ' $n$ gestalte van die verkondiging wat gerig is aan hulle wat nie-meer-glo-nie.

\section{KONKLUSIE}

Die probleem van kerklosheid en kerkloosheid is akuut. As dit vir die kerk 'n saak van erns is om aan hierdie probleem aandag te gee (wat hy nie kan negeer nie), sal die kerk dit sistematies en op geordende wyse moet doen. Om dit werklik sinvol aan te pak sal die kerk noodwendig die onderskeid tussen pastoraat en evangelisasie moet handhaaf.

\section{Verwysinge}

1. Dit kan vasgestel word uit notules van die ouderlinge- en kerkraadsvergaderings van die Nederduitsch Hervormde Gemeente Hartebeestpoort.

2. Die wyse van beëindiging van lidmaatskap kan nie hier bespreek word nie, aangesien dit 'n studie op sigself is. Nogtans wil ek die moontlikheid oophou dat dit sonder die formulier van die ban kan geskied, bloot deur die rojering in die lidmaatregister en die amptelike bekendmaking in die gemeente.

\section{Literatuurverwysings}

Beukes, JA 1983. Hedendaagse evangelisasie - 'n Evangelisasiemetode met die oog op die kerk se werk in ' $n$ digbevolkte stadsgemeenskap. Pretoria: Universiteit van Pretoria. (Ongepubliseerde DD-proefskrif).

De Klerk, JJ et al 1979. Evangelistiek. Pretoria.

De Wet, JI s a. Inleiding tot die Praktiese Teologie. Ongepubliseerde kernaantekeninge, Departement Praktiese Teologie (Afdeling A), Universiteit van Pretoria.

Malan, MD 1983. Die besondere pastoraat tot die kerklosse. Pretoria: Universiteit van Pretoria. (Ongepubliseerde BD-skripsie).

Margull, HJ 1959. Theologie der missionarischen Verkundigung. Stuttgart.

Walker, W 1968. A history of the Christian church. Edinburgh. 